\title{
Fisheries-induced evolution: present status and future directions
}

\author{
Richard Law* \\ Biology Department, University of York, York YO10 5YW, UK
}

\begin{abstract}
This essay comments on recent research on Darwinian fisheries science and on the future development of this field. From a practical point of view, the key question is: how fast are evolutionary changes caused by fishing happening? To answer this question, there is a need to understand intensities of selection generated by fishing, heritabilities and genetic correlations of the traits under selection, and whether the rates of change in traits predicted from this information are consistent with the changes observed. Although there is little doubt about the existence of phenotypic change in life-history traits of exploited fish stocks, there are few direct estimates of selection differentials caused by fishing. Results that are available, together with the relatively low heritabilities of life-history traits, suggest that the evolution caused by fishing occurs at a modest rate, and is likely to need a decadal time scale to be clearly observable. Given the pressing need for attention to fisheries in the short term, measures to control the longer-term evolutionary impact of fishing are most likely to be adopted if they also help to meet short-term objectives of management. With this in mind, the essay mounts a defence of large, old fish, the presence of which would be beneficial to stocks in the short term, and the conservation of which would set in motion selection for improved growth in the longer term.
\end{abstract}

KEY WORDS: Darwinian fisheries science - Evolution · Fisheries · Heritability · Life history • Maturation reaction norm $\cdot$ Selection differential $\cdot$ Selection response

\section{INTRODUCTION}

Over the last few years there has been a major increase in interest in Darwinian fisheries science, a term given to the study of evolution in fish stocks generated by fisheries (Conover 2000). This short essay comments on some of the progress in this field, and the debates that this research is leading to. These debates are mostly to do with the interpretation of probabilistic maturation reaction norms, which describe the probability of maturing as a function of age and size (Heino et al. 2002).

The essay also considers future management measures that might help to deal with fisheries-induced evolution, arguing that such measures are most likely to be adopted if they also support short-term objectives of management. Given the circumstances, the essay mounts an unashamed defence of big, old fish, on the grounds that both the short- and long-term health of fish stocks could benefit from giving them more protection against exploitation.

\section{PREDICTED RATES OF CHANGE IN LIFE-HISTORY TRAITS}

The key question from a practical perspective is: how quickly can fishing activities cause evolution in fish stocks? Fisheries-induced evolution is relevant to fisheries management if it happens on a time scale of years, but is of less immediate consequence if it happens on a time scale of hundreds of years. It is the quantitative rate (rather than the qualitative existence) of change that is most important to know about for practical purposes.

The life-history traits under selection are typically quantitative, determined both by environmental con- 
ditions and by many genes with small effects. The standard modelling framework with which to address evolutionary questions of this kind is provided by quantitative genetics (Falconer \& Mackay 1996). Quantitative genetics provides a simple recurrence relation to describe the selection response $R$, the change in the mean value of a quantitative trait from one generation to the next, in the short term, under directional selection:

$$
R=h^{2} S
$$

Here $S$ is the selection differential, the difference between the mean value of the trait before and after selection within a generation, and $h^{2}$ is the heritability of the trait, which is measured as the additive genetic variance divided by the total phenotypic variance (Falconer \& Mackay 1996). We can therefore examine the heritabilities and the fisheries-induced selection differentials to gain some preliminary understanding of the rate of evolution.

\section{Heritabilities}

An organism's life-history broadly comprises the age- and size-dependent schedule of growth, survivorship and fecundity. There is no suggestion that the traits that make up the life history have to represent the coordinated expression of a set of genes controlling particular developmental pathways (Thorpe 2007, this Theme Section). It is enough that there exists additive genetic variance in the traits on which selection can operate.

Heritabilities are low in life-history traits in comparison with traits less closely coupled to fitness (Mousseau \& Roff 1987). Compilations from the aquaculture industry suggest that values in the range 0.2 to 0.3 are often appropriate (Law 2000). Research conducted in the last few years supports this view; for instance, using full-sib families (within populations) reared in tanks, Gjerde et al. (2004) reported a heritability for weight of cod Gadus morhua at age $200 \mathrm{~d}$ of 0.3 . Heritabilities could be smaller in the wild where environmental variation might well be greater; however, information is much harder to obtain in these circumstances. Nevertheless, a study into the potential for sea ranching of Atlantic salmon Salmo salar obtained a heritability of 0.36 for body weight after 1 winter at sea, similar to that found in experimental farms (Jónasson et al. 1997). In a similar way, Funk et al. (2005) were able to estimate heritabilities and genetic correlations of morphological and life-history traits of pink salmon Oncorhynchus gorbuscha on their return from the sea to spawn. Heritabilities of length were approximately $0.4 ;$ however, those of egg number and weight - the traits most closely related to fitness were not significantly different from zero. Surprisingly, estimates of heritability in the wild in general are not radically different from those obtained under more controlled conditions (Weigensberg \& Roff 1996).

Further evidence for the existence of genetic variation in the wild comes from differences in growth of cod sampled from different locations in the Northwest Atlantic when reared in a common environment (Purchase \& Brown 2001). The same applied in a comparison of Northeast Arctic and Norwegian coastal cod (Svåsand et al. 1996). Imsland \& Jonsdottir (2002) were cautious in attributing these differences to genetic causes because of the possible carryover of environmental effects from the wild into the common environment, and because the sample sizes were quite small; nevertheless, they were confident that there was a genetic component to growth in turbot Psetta maxima and halibut Hippoglossus hippoglossus. Also indicative of genetic variation in the wild is the existence of counter-gradient variation, where genes for faster growth compensate for the lower temperature and slower growth in populations at higher latitudes. Counter-gradient variation has been documented in several fish species, including populations of Atlantic silverside Menidia menidia reared in a common environment (Conover \& Present 1990, Conover et al. 2005).

\section{Selection differentials}

A priori one might expect selection differentials caused by fishing to be substantial in view of the fact that fishing mortality rates are large and that fishing gear is often selective. Estimates of selection differentials generated by fishing are rare; however, early work on cod in part of the North Sea from 1984 to 1990 suggested that length-at-age was reduced by approximately $1 \mathrm{~cm}$ through selective fishing during the period when a cohort was entering the fishery (Law \& Rowell 1993).

An extensive study on cod in the Gulf of St. Lawrence estimated selection differentials by backcalculating earlier length-at-age of surviving individuals from records of size retained in their otoliths (Sinclair et al. 2002a). They obtained selection differentials for the most part in the range -4 to $+4 \mathrm{~cm}$. This study is of special interest because there was a change from a selection differential in favour of individuals with greater length-at-age in the 1970s to one favouring those with lower length-at-age in the 1980s and early 1990s. Fishing mortality on this stock was strongly dome-shaped, being greatest on fish of intermediate body size (Sinclair 1998), probably because 
fishing was mostly at water depths at which these fish were most abundant; large cod tend to be at greater depths (Swain 1993). The positive selection differential in the 1970s is consistent with this dome-shaped fishing mortality: individuals growing rapidly through the sizes most vulnerable to fishing would be favoured by virtue of their shorter period of vulnerability. However, abundance of the stock increased in the late 1970s, correlated with an overall reduction in the growth of individuals (Sinclair et al. 2002b), and it is suggested that slower growth, delaying entry into the fishery, then became more advantageous. This study illustrates how fishing coupled with spatial separation of size classes and environmental change can have quite subtle effects on selection.

Selection differentials of this magnitude, together with long generation times and low heritabilities of life-history traits, suggest that selection responses while important - are likely to be quite modest on a year-to-year basis, and more likely to be detected from one decade to another than from one year to the next.

\section{OBSERVED RATES OF CHANGE IN LIFE-HISTORY TRAITS}

Evidence of temporal change in life-history traits of fish stocks was reviewed by Law (2000), and continues to accumulate. For instance, Hutchings (2005) documented a decline in age at maturation in 2 stocks of cod in the Northwest Atlantic: one stock that extends from Labrador southeast to the northern part of the Grand Banks, and another from the eastern Scotian Shelf. These results are consistent with those of earlier studies (Trippel et al. 1997). A study on reproductive investment by North Sea plaice Pleuronectes platessa over a period that began in the 1960s did not strongly suggest a change owing to fishing; however, there was a possibility of some change since the late 1940s (Rijnsdorp et al. 2005). Changes in maturation reaction norms are covered separately below.

Although there is much evidence for the existence of changes in life-history traits of exploited fish stocks, it is less clear whether the observed rates of change in life histories are quantitatively consistent with the likely heritabilities and selection differentials generated by fishing. To date, I am only aware of 1 study that brings together both the selection differential estimated from the catch data on a stock and a time series showing phenotypic change in a life-history trait. This is a study on Icelandic haddock Melanogrammus aeglefinus, motivated by a continuing downward trend in length-at-age of this stock, not easily accounted for by environmental factors (Thordarson 2005). This research has yet to be published, and shows a close match between the rate of phenotypic change and the selection differential, under a reasonable assumption about the heritability.

The difficulty of obtaining quantitative agreement between observed and predicted rates of change is evident in size at maturation of the Baltic cod (K. Andersen pers. comm.). A quantitative-genetic model suggested a decline in size at maturation by about $40 \mathrm{~g}$ per generation, a rate that has not been observed during the period of heavy exploitation since the 1950s. He suggested that a number of biological features absent from the model, such as greater quality of eggs from older fish, might help to reduce the discrepancy. An interesting feature of this analysis is that selection on size at maturation was disruptive: individuals with intermediate sizes at maturation had lower fitness than those with maturation at small or large sizes. Disruptive selection of this kind was also a property of a model of a size-structured, resource-consumer population under size-dependent harvesting (de Roos et al. 2006). A feature of this study was that fisheriesinduced selection could cause an evolutionary regime shift such that the evolution of maturation at small sizes under harvesting would then be difficult to reverse.

Overall, there is little doubt about the existence of phenotypic change in the life-history traits of exploited fish stocks. However, the quantitative analysis of whether rates of change are consistent with likely heritabilities and selection differentials caused by fishing, allowing for change in the environment, is a critical issue needing more research.

\section{THE MATURATION REACTION NORM AS AN INDICATOR OF GENETIC CHANGE}

Much of the recent work on fisheries-induced evolution has centred on probabilistic reaction norms for maturation (Heino et al. 2002). This reaction norm describes the probability of maturing as a function of age and size, and is often depicted as a sequence of points in an age-size space along which the probability of maturing is 0.5 . It is important to bear in mind that the maturation reaction norm is just one of a number of traits potentially liable to evolve through the operation of fisheries. Other traits include, for instance, growth (Thordason 2005), reproductive effort (Rijnsdorp et al. 2005) and morphology (Hamon et al. 2000). Changes in traits such as these may also be important for the health of wild fish stocks.

One reason why there is so much current research on maturation reaction norms is that, although individual growth itself is highly variable and contingent on the environment, the combinations of size and age at 
which maturation occurs could be relatively insensitive to environment-induced variability. With this in mind, change over time in the reaction norm is interpreted as a signal of evolutionary (i.e. genetic) change, in contrast to variation in growth within a single reaction norm that is taken to reflect effects of the environment (Barot et al. 2004, Olsen et al. 2005). This idea is of much interest, but appears to be an assumption rather than an empirically verified observation in the context of marine fish stocks.

In fact, there is evidence that the environment can have substantial effects on maturation reaction norms based on size and age. This is evident for instance in the Northeast Arctic cod, in which age at maturation has been decreasing since the 1940s (Jørgensen 1990). Marshall \& McAdam (2007, this Theme Section) show striking evidence of a shift in the feeding conditions for cod in the Barents Sea in the 1980s. Before 1980, the cod had lower weight-at-age at age 7 to $10 \mathrm{yr}$ than after 1984, and a smaller proportion were mature in the earlier period. Accompanying this shift was a rather abrupt change in the length at $50 \%$ maturation of $6 \mathrm{yr}$ old cod. This suggests that the maturation reaction norm was directly affected by a change in environmental conditions. Major environmental changes have been taking place in the Barents Sea, including increasing water temperatures since about 1980, and large fluctuations in the availability of capelin Mallotus villosus and herring Clupea harengus, which form an important part of the diet of this cod stock (Hjermann et al. 2007, D. Ø. Hjermann pers. comm., C. Marshall pers. comm.). However, the exact environmental cause of the change in maturation is not yet known.

The abrupt change in maturation of Northeast Arctic cod in the 1980s does not account for the longer-term decline in age at maturation over the 20th century, for which the most parsimonious explanation is evolution caused by development of a fishery on the feeding grounds early in the century. Although it has not been easy to achieve a close match between the rapid observed decline and that predicted by quantitative genetic models (Jørgensen 2005), results of recent models get quite close to the decline observed in the stock (C. Jørgensen pers. comm.).

A second piece of evidence for a direct effect of the environment on the reaction norm is a finding that maturation in chum salmon Oncorhynchus keta is better predicted by recent growth history of an individual than by its body size (Morita \& Fukuwaka 2006). This is important because the maturation reaction norm then depends on prevailing features of the environment, such as availability of food, as opposed to being determined by a combination of age and size alone.

Third is a study by Olsen et al. (2004) that interpreted change in length at $50 \%$ maturity of cod aged 5 and 6 yr in the Northwest Atlantic as indicative of rapid evolution. An interesting feature of the results is that the direction of change in the time series altered within about $3 \mathrm{yr}$ of the 1992 fishing moratorium, i.e. in cohorts in place before the moratorium was imposed. This change was consistent across the 3 areas documented and seems unlikely to be a consequence of noise (Fig. 3 in Olsen et al. 2004; see particularly the 5 yr old cod). A change so soon after the moratorium is evidence that pre-existing cohorts were responding in some way to the new environment, rather than evidence of an inherited genetic response. This is because information about the selection response becomes available only when the first cohorts born after the moratorium are reaching maturity 5 or 6 yr later. Such a change might reflect a phenotypic adjustment to the new environmental conditions without selection, indicating an environmental influence on this component of the reaction norm. In addition, such a change might reflect a selection differential generated by the new environmental conditions. In this latter case, it is interesting that in 2 of the 3 areas, change in cohorts born after the moratorium was small compared with change in cohorts in place at the time of the moratorium (Fig. 3 in Olsen et al. 2004). The lack of continuing change would suggest that the heritability of the trait was low. In either case, the post-moratorium time series suggest a substantial environmental influence on the component of maturation reaction norm investigated.

Apart from the evidence that the environment affects the maturation reaction norm, the evidence also suggests that there remains a substantial component of genetic, as well as environmental, variation in sizeat-age in the wild. The best evidence comes from the studies on Atlantic salmon and pink salmon mentioned earlier (Jónasson et al. 1997, Funk et al. 2005). Other evidence is more circumstantial because it is based on heritability estimates on growth in experimental conditions. However, bearing in mind the findings of Weigensberg \& Roff (1996), and the existence of counter-gradient variation (Conover \& Present 1990, Conover et al. 2005), it would be surprising if genetic variation in size-at-age was not a common feature of fish populations in the wild.

On the basis of the evidence currently available, it therefore seems that the use of maturation reaction norms to disentangle genotypic and environmental effects does not yet have a strong empirical foundation. Some part of the variation in the maturation reaction norm is likely to be genetic, and some part of the changing maturation in fish stocks over time is likely to represent evolution. But, as with other life-history traits considered in the context of fisheries-induced evolution, there remains uncertainty about the relative strength of environmental and genetic signals. 
It may be best to think of a life history as a set of correlated traits with potentially some genetic component to the correlations. The correlations matter because the effects of fisheries-induced selection then depend in part on them: when selection is applied to one trait, changes may occur in other correlated traits. For instance, Munch et al. (2005) found in Atlantic silverside that a size-selective harvest at age $190 \mathrm{~d}$ caused a detectable selection response for length at earlier ages, down to 90 d (see also Kirkpatrick 1993); however, correlated genetic changes for early life-history traits affecting recruitment were not evident. Genetic correlations also matter because fishing can be selective in various ways and probably acts on more than 1 trait at a time. As Hard (2004) noted in a quantitative-genetic study of the Chinook salmon Oncorhynchus tshawytscha, selection on correlated traits has the potential to be mutually reinforcing, so that the overall response is greater than would be expected from analysis of single traits in isolation. In practice, genetic correlations are hard to estimate, but some clues may be obtained from the phenotypic correlations of traits (Cheverud 1988, Roff 1995). For example, Funk et al. (2005) found a positive relationship between genetic and phenotypic correlations of traits in pink salmon; however, they suggested caution in adopting this approach because the relationship was sometimes lost.

Gaining knowledge of fisheries-induced evolution is not an easy task, and recent research on maturation reaction norms is an interesting attempt to disentangle the effects of genetic and environmental processes in genetically correlated life-history traits. However, it is important for biologists who work on fisheries to bear in mind that, while there can be no doubt that fishing causes genetic change in life histories, the rates of these changes remain uncertain.

\section{TO THE FUTURE: IN DEFENCE OF BIG FISH}

Decision making in management of fisheries tends to give greatest weight to the short term because the state of fish stocks and marine ecosystems a few years into the future is the most pressing priority. Fisheriesinduced evolution is more subtle and gradual, but also of great importance if we are to leave healthy fish stocks for the future. However, the management focus on the short term suggests that longer-term Darwinian goals are most likely to be achieved if they are based on measures that also help to meet short-term goals. This leads to the question: are there management measures that would help in the short term, and that might also help to reverse longer-term evolutionary changes if these are thought to be deleterious to the stocks themselves or to the objectives of management?
Arguably, a key measure is to protect large, old fish within populations. This is not to question the importance of protecting small, young fish, currently an important driver of contemporary fisheries management and enshrined, for instance, as a major factor for the conservation of fish stocks in the Common Fisheries Policy of the European Union (Anon 2002). However, in our concern to protect young fish, we have been less concerned about the fate of larger, older fish within populations. Large, old fish do matter in both the short- and the long term for the reasons that follow.

In the short term of population dynamics, concentrating just on the protection of small, young fish leads to truncation of the size and age distributions (e.g. Ottersen et al. 2006). This makes fisheries increasingly dependent on young, inexperienced spawners that are less fecund and produce eggs and larvae of lower quality (Trippel 1995, Berkeley et al. 2004, Birkeland \& Dayton 2006). This is deleterious for stock renewal; for instance, a low age diversity, corresponding to a large proportion of young individuals, is correlated with poor recruitment in Icelandic cod (Marteinsdottir \& Thorarinsson 1998; see also Secor 2000). More generally, the truncation of the age structure caused by fishing removes a buffer against years of poor recruitment and exacerbates fluctuations in year-class strength. Hsieh et al. (2006) documented the temporal variability in larval population densities of 29 species, some exploited and some unexploited, over a $50 \mathrm{yr}$ period. Fluctuations were greater in the exploited species than in the unexploited ones, a phenomenon that they attributed to truncation of age distributions owing to exploitation.

In the longer (evolutionary) term, failure to protect large, old fish may generate selection pressures that are deleterious to growth of fish. Individuals that pass more time before reaching a size at which they become vulnerable to fishing leave more descendants, all other things being equal. Evidence to support this comes from the selection differential for reduced length-atage observed in Gulf of St. Lawrence cod in the 1980s and 1990s, when there seems to have been little opportunity for growing beyond a catchable size (Sinclair 2002a,b). Also, individuals that mature when smaller run less risk of being caught before maturation and leave more offspring, all other things being equal (caveats to this reasoning are discussed below).

In sum, there are benefits in both the short and longer term of maintaining large, old individuals within populations. As a management objective, this ought to be relatively uncontroversial: large fish have become so rare as a result of current fishing practices that the loss in yield arising from their protection should be relatively small. This is with the caveats that some reduction in fishing mortality at smaller sizes could be needed if a build-up of large fish was to be 
achieved rapidly, and that large fish sometimes have intrinsically greater market value. It is important to achieve a reduction in fishing mortality on large fish without increasing fishing mortality on smaller fish, which would obviously be highly detrimental to fish stocks. Also, an awareness that large fish are potential predators of smaller fish is needed, and there could be circumstances in which this is deleterious to the yield.

In practice, protection of both of small and large fish requires patterns of fishing mortality that are greatest in fish of intermediate body size (dome-shaped fishing mortality). Such fishing mortality patterns are already in place in sports fisheries, such as slot-limit sturgeon fisheries in Washington State, and in commercial trap fisheries, such as the Maine lobster fishery. Some fishing gears, such as traps, gill nets and long lines, can be quite size selective in any event (Myhre 1969, Hamley 1975). Other gears can be made more size selective, for instance by using excluder devices for large fish on trawl nets, and by using maximum trawl times and speeds to make it easier for large fish to escape. Compromises are always going to be needed in multispecies fisheries. Marine protected areas (MPAs) for fish could help substantially in reducing selective effects of fisheries. A detailed model-based analysis of MPAs found that they could be as effective as other management tools at protecting stocks against fisheries-induced selection for early maturation (Baskett et al. 2005). To the extent that fish of different life stages live in different places, MPAs may be targeted at some life stages in preference to others, although the effects of such targeting could be counter-intuitive. For instance, it seems possible that protecting fish on spawning grounds, important in short-term management, could favour life histories in which fish mature and move to the protection of the spawning grounds at an earlier age.

There are several caveats to bear in mind. Blanket recommendations are dangerous, and measures for protecting large fish are best developed on a stockby-stock basis to ensure that they are appropriate in context. It is also dangerous to develop management policies before the core science is available; for instance, dome-shaped fishing mortality could generate disruptive rather than directional selection. However, such points need to be balanced against an awareness that (1) many fish stocks no doubt already experience fisheries-induced selection, limited though our understanding of this is, (2) the resulting evolution may be hard to reverse, and (3) the precautionary principle places responsibility on us to leave our resources in a state that can be utilised as fully by our descendants as by ourselves. The full evolutionary picture is, of course, a good deal more complicated than given in this short commentary, depending on the balance between natural mortality and fishing mortality, the rate of growth and the size-dependence of egg production, the genetic architecture of the life history, the selection differentials generated by fishing, and the population dynamics.

\section{CONCLUSIONS}

The current interest in fisheries-induced evolution draws attention to this important, but previously neglected, subject. At the same time, it needs to be understood that the rates of genetic change are likely to be modest on a year-to-year basis. Given all the circumstances, it seems sensible to work towards measures that will help to resolve current short-term problems, and that will simultaneously generate selection regimes likely to help in the longer term. Taking greater care of larger, older fish seems especially important in this regard. This essay therefore joins the growing voice of opinion that argues that these fish should be given more protection than they receive at present (e.g. Trippel 1995, Conover \& Munch 2002, Birkeland \& Dayton 2005).

Acknowledgements. Thanks to D. Ø. Hjermann, S. Jennings, C. Jørgensen, C. T. Marshall, J. D. Reynolds, D. P. Swain and G. Thordason for helpful discussions during the preparation of this essay, and to the University of Calgary where this work was completed.

\section{LITERATURE CITED}

Anon (2002) Proposal for a Council Regulation on the conservation and sustainable exploitation of fisheries resources under the Common Fisheries Policy. Commission of the European Communities, Brussels

Barot S, Heino M, O'Brien L, Dieckmann U (2004) Long-term trend in the maturation reaction norm of two cod stocks. Ecol Appl 14:1257-1271

Baskett ML, Levin SA, Gaines SD, Dushoff J (2005) Marine reserve design and the evolution of size at maturation in harvested fish. Ecol Appl 15:882-901

Berkeley SA, Chapman C, Sogard SM (2004) Maternal age as a determinant of larval growth and survival in a marine fish, Sebastes melanops. Ecology 85:1258-1264

Birkeland C, Dayton PK (2005) The importance in fishery management of leaving the big ones. Trends Ecol Evol 20:356-358

Cheverud JM (1988) A comparison of genetic and phenotypic correlations. Evolution 42:958-968

Conover DO (2000) Darwinian fishery science. Mar Ecol Prog Ser 208:303-307

Conover DO, Munch SB (2002) Sustaining fisheries yields over evolutionary time scales. Science 297:94-96

Conover DO, Present TMC (1990) Countergradient variation in growth rate: compensation for length of the growing season among Atlantic silversides from different latitudes. Oecologia 83:316-324

Conover DO, Arnott SA, Walsh MR, Munch SB (2005) Darwinian fishery science: lessons from the Atlantic silverside (Menidia menidia). Can J Fish Aquat Sci 62:730-737

de Roos AM, Boukal DS, Persson L (2006) Evolutionary regime 
shifts in age and size at maturation of exploited fish stocks. Proc R Soc Lond B 273:1873-1880

Falconer DS, Mackay TFC (1996) Introduction to quantitative genetics, 4th edn. Longman, Harlow

Funk WC, Tyburczy JA, Knudsen KL, Lindner KR, Allendorf FW (2005) Genetic basis of variation in morphological and life-history traits of a wild population of pink salmon. J Hered 96:24-31

Gjerde B, Terjesen BF, Barr Y, Lein I, Thorland I (2004) Genetic variation for juvenile growth and survival in Atlantic cod (Gadus morhua). Aquaculture 236:167-177

Hamley JM (1975) Review of gillnet selectivity. J Fish Res Board Can 32:1943-1969

Hamon TR, Foote CJ, Hilborn R, Rogers DE (2000) Selection on morphology of spawning wild sockeye salmon by a gillnet fishery. Trans Am Fish Soc 129:1300-1315

Hard JJ (2004) Evolution of chinook salmon life history under size-selective harvest. In: Hendry AP, Stearns SC (eds) Evolution illuminated: salmon and their relatives. Oxford University Press, Oxford, p 315-337

Heino M, Dieckmann U, Godø OR (2002) Estimating reaction norms for age and size at maturation with reconstructed immature size distributions: a new technique illustrated by application to Northeast Arctic cod. ICES J Mar Sci 59: 562-575

Hjermann DØ, Bogstad B, Eikeset AM, Ottersen G, Gjøsaeter $H$, Stenseth NC (2007) Food web dynamics affect Northeast Arctic cod recruitment. Proc R Soc Lond B 274: 661-669

Hsieh CH, Reiss CS, Hunter JR, Beddington JR, May RM, Sugihara G (2006) Fishing elevates variability in the abundance of exploited species. Nature 443:859-862

Hutchings JA (2005) Life history consequences of overexploitation to population recovery in Northwest Atlantic cod (Gadus morhua). Can J Fish Aquat Sci 62:824-832

Imsland AK, Jónsdóttir ODB (2002) Is there a genetic basis to growth in Atlantic cod? Fish Fish 3:36-52

Jørgensen C (2005) Fisheries-induced life history evolution in cod. PhD Thesis, University of Bergen, Norway

Jørgensen T (1990) Long-term changes in age at sexual maturity of Northeast Arctic cod (Gadus morhua L.). J Cons Int Explor Mer 46:235-248

Jónasson J, Gjerde B, Gjedrem T (1997) Genetic parameters for return rate and body weight of sea-ranched salmon. Aquaculture 154:219-231

Kirkpartick M (1993) Evolution of size and growth in harvested natural populations. In: Stokes TK, McGlade JM, Law $\mathrm{R}$ (eds) The exploitation of evolving resources. Lecture notes in biomathematics 99. Springer-Verlag, Berlin, p 145-154

Law R (2000) Fishing, selection and phenotypic evolution. ICES J Mar Sci 57:659-668

Law R, Rowell CA (1993) Cohort-structured populations, selection responses, and exploitation of the North Sea cod. In: Stokes TK, McGlade JM, Law R (eds) The exploitation of evolving resources. Lecture notes in biomathematics 99. Springer-Verlag, Berlin, p 155-173

Marshall CT, McAdam BJ (2007) Integrated perspectives on genetic and environmental effects on maturation can reduce the potential for errors of inference. Mar Ecol Prog Ser 335:301-310

Marteinsdottir G, Thorarinsson K (1998) Improving the stockrecruitment relationship in Icelandic cod (Gadus morhua) by including age diversity of spawners. Can J Fish Aquat Sci 55:1372-1377

Morita K, Fukuwaka MA (2006) Does size matter most? The effect of growth history on probabilistic reaction norm for salmon maturation. Evolution 60:1516-1521

Editorial responsibility: Howard Browman (Associate Editorin-Chief), Storebø, Norway
Mousseau TA, Roff DA (1987) Natural selection and the heritability of fitness components. Heredity 59:181-197

Munch SB, Walsh MR, Conover DO (2005) Harvest selection, genetic correlations, and evolutionary changes in recruitment: one less thing to worry about? Can J Fish Aquat Sci 62:802-810

Myhre RJ (1969) Gear selection and Pacific halibut. Report No. 51. International Pacific Halibut Commission, Seattle, WA

Olsen EM, Heino M, Lilly GR, Morgan MJ, Brattey J, Ernande B, Dieckmann U (2004) Maturation trends indicative of rapid evolution preceded the collapse of northern cod. Nature 428:932-935

Olsen EM, Lilly GR, Heino M, Morgan MJ, Brattey J, Dieckmann U (2005) Assessing changes in age and size at maturation in collapsing populations of Atlantic cod (Gadus morhua). Can J Fish Aquat Sci 62:811-823

Ottersen G, Hjermann DØ, Stenseth NC (2006) Changes in spawning stock structure strengthens the link between climate and recruitment in a heavily fished cod stock. Fish Oceanogr 15:230-243

Purchase CF, Brown JA (2001) Stock-specific changes in growth rates, food conversion efficiencies, and energy allocation in response to temperature change in juvenile Atlantic cod. J Fish Biol 58:36-52

Rijnsdorp AD, Grift RE, Kraak SBM (2005) Fisheries-induced adaptive change in reproductive investment in North Sea plaice (Pleuronectes platessa)? Can J Fish Aquat Sci 62:833-843

Roff DA (1995) The estimation of genetic correlations from phenotypic correlations: a test of Cheverud's conjecture. Heredity 74:481-490

Secor DH (2000) Spawning in the nick of time? Effect of adult demographics on spawning behaviour and recruitment of Chesapeake Bay striped bass. ICES J Mar Sci 57:403-411

Sinclair AF (1998) Estimating trends in fishing mortality at age and length directly from research survey and commercial catch data. Can J Fish Aquat Sci 55:1248-1263

Sinclair AF, Swain DP, Hanson JM (2002a) Measuring changes in the direction and magnitude of size-selective mortality in a commercial fish population. Can J Fish Aquat Sci 59:361-371

Sinclair AF, Swain DP, Hanson JM (2002b) Disentangling the effects of size-selective mortality, density, and temperature on length-at-age. Can J Fish Aquat Sci 59:372-382

Svåsand T, Jørstad KE, Otterå H, Kjesbu OS (1996) Differences in growth performance between Arcto-Norwegian and Norwegian coastal cod reared under identical conditions. J Fish Biol 49:108-119

Swain DP (1993) Age- and density-dependent bathymetric pattern of Atlantic cod (Gadus morhua) in the southern Gulf of St Lawrence. Can J Fish Aquat Sci 50:1255-1264

Thordarson G (2005) Growth and maturation of Icelandic haddock and their implications for management. PhD Thesis, Imperial College, London

Thorpe JE (2007) Maturation responses of salmonids to changing developmental opportunities. Mar Ecol Prog Ser 335:285-288

Trippel EA (1995) Age at maturity as a stress indicator in fisheries. BioScience 35:759-771

Trippel EA, Morgan MJ, Fréchet A, Rollet C, Sinclair A, Annand C, Beanlands D, Brown L (1997) Changes in age and length at sexual maturity of northwest Atlantic cod, haddock and pollock stocks, 1972-1995. Can Tech Rep Fish Aquat Sci 2157

Weigensberg I, Roff DA (1996) Natural heritabilities: can they be reliably estimated in the laboratory? Evolution 50: $2149-2157$

Submitted: August 3, 2006; Accepted: December 13, 2006 Proofs received from author(s): March 13, 2007 